\title{
HIGH TEMPERATURE PEM FUEL CELL STACKS WITH ADVENT TPS MEAS
}

\author{
Stylianos Neophytides $^{(1)}$, Maria K. Daletou ${ }^{(1)}$, Nikolaos Athanasopoulos ${ }^{(2)}$, Nora Gourdoupi ${ }^{(2)}$, \\ Emory De Castro( ${ }^{(2)}$, Max Schautz $^{(3)}$ \\ ${ }^{(1)}$ Foundation of Research and Technology-Hellas, Institute of Chemical Engineering Sciences FORTH/ICE-HT, Patras \\ 26504, Greece, Email: neoph@iceht.forth.gr \\ (2) Advent Technologies S.A., Patras Science Park, Stadiou Street, Patras26504, Greece, Email:ngourdoupi@advent- \\ energy.com \\ (3) European Space Research and Technology Centre (ESTEC), The Netherlands, Email: max.schautz@esa.int
}

\begin{abstract}
High power/high energy applications are expected to greatly benefit from high temperature Polymer Electrolyte Membrane Fuel Cells (PEMFCs). In this work, a combinatorial approach is presented, in which separately developed and evaluated MEAs, design and engineering are employed to result in reliable and effective stacks operating above $180^{\circ} \mathrm{C}$ and having the characteristics well matched to applications including auxiliary power, micro combined heat and power, and telecommunication satellites.
\end{abstract}

\section{INTRODUCTION}

The high temperature polymer electrolyte membrane fuel cells (HT PEMFCs) offer significant flexibility when used as energy converters in stationary, mobile and portable power devices. When compared to low temperature PEM fuel cells, subsystems for membrane humidification and carbon monoxide clean up can be eliminated. In addition to simplifying fuel cell systems, when used in electrolysis mode, dilute, contaminated hydrogen can be concentrated and purified.

Fuel cell components such as the electrocatalyst and electrode, microporous layer, membrane, gaskets, compression assembly elements, bipolar plates, end plates etc. are of great importance.

The Membrane Electrode Assembly (MEA) is the core component of the stack and should have specific properties to withstand the strong conditions during the fuel cell operation. The state of the art MEA technology is based on $\mathrm{H}_{3} \mathrm{PO}_{4}$ imbibed polymer electrolytes and $\mathrm{Pt}$ based catalysts. The most widely used and studied polymer for HT PEMFC is polybenzimidazole (PBI) and its derivatives imbibed with phosphoric acid since this class has excellent mechanical and thermal properties and high ionic conductivity under anhydrous conditions. A stability of $>18,000 \mathrm{hrs}$ of continuous operation has been recorded [1]. Alternative polymers that have gained ground in recent years are pyridine based aromatic polyethers [2]. The acid-base interactions between these types of polymers and the phosphoric acid results in ionic materials that are highly conductive and have shown very promising results during the fuel cell operation for 4,000 hrs [3].

In addition to the MEA, the performance of a PEM fuel cell stack is affected by many internal and external factors, such as fuel cell design and assembly, degradation of materials, operational conditions, and impurities or contaminants. Furthermore, the design and the concept of a HT PEMFC stack are mainly determined by the application and the environmental conditions, and in most cases cost and weight limitations need to be considered.

For example in space applications, where regenerative fuel cells could become the superior choice as an alternative to rechargeable (secondary) batteries, a lightweight system is the most critical requirement.

This work focuses on the design and manufacturing of: -HT PEM fuel cells stacks of $1 \mathrm{~kW}$ electrical and $1 \mathrm{~kW}$ thermal power for APU and CHP applications using graphite resin bipolar plates and Advent's TPS ${ }^{\circledR}$ MEAs. -Design of HT PEM fuel cell of $3 \mathrm{~kW}$ electric power using metal bipolar plates and Advent TPS MEAs for regenerative PEM fuel cell system for telecommunication satellites.

\section{RESULTS AND DISCUSSION}

\subsection{HTPEM FC stacks with graphite plates for APU and CHP applications.}

Based on our previous experience the active area of choice for a HT PEMFC of $1 \mathrm{~kW}$ electric power output is $177 \mathrm{~cm}^{2}$ for APU and CHP applications. The first step was to build an air cooled stack in order to study the bipolar plate design, the gaskets and the operation of the stack at $1 \mathrm{~kW}$. For its construction, 36 Advent TPS MEAs of $177 \mathrm{~cm}^{2}$ active area (GDE area $191 \mathrm{~cm}^{2}$ ) were used.

The individual MEA parts are shown in Figure 1.

The 36-MEAs stack system -which was used as a "proof of concept"- was manufactured utilizing materials such as stainless steel end plates, graphite composite bipolar plates with fins, gold plated current collectors, cartridge heater for start up, which were not optimized in terms of design, weight and volume. 


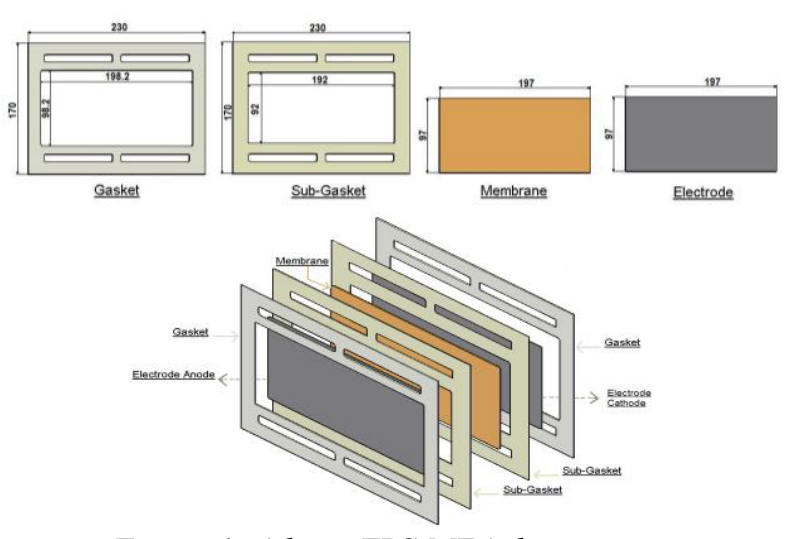

Figure 1: Advent TPS MEA dimensions.

The material of the bipolar plate was a composite of graphite and polymer resin and the flow field was based on a design of prior knowledge. This has been modified accordingly at the inlets and outlets of the gases in order to cope with possible internal leaks. As shown in Fig.2, the fins of the plates were used for the air cooling approach.

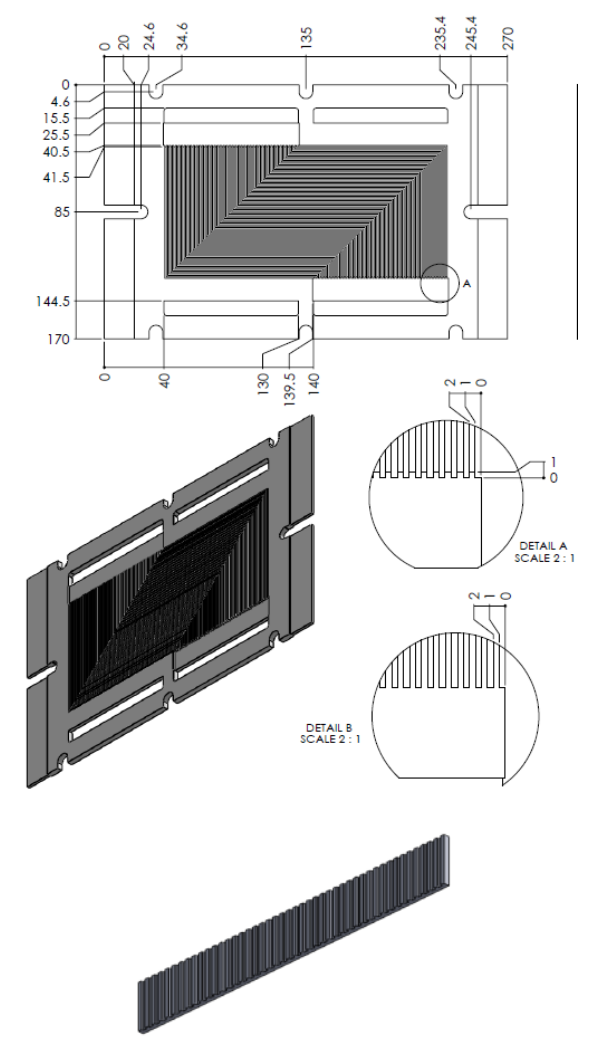

Figure 2: View of the top side of the bipolar plate and block for inlet and outlet of the gases.

Upon assembly, the stack (Picture 1) was checked and found free of external (from the stack core out) and internal leakages (from one compartment to another). The stack was consequently coupled with a steam reforming LPG/LNG fuel processor. For the start up of the stack, cartridges were placed on the bipolar plates edges (cartridges' temperature was $200^{\circ} \mathrm{C}$ ).

The MEA performance was consistent and the power output of $1 \mathrm{~kW}$ was reached as shown in Fig. 3 using reformate gas $\left(80.4 \% \mathrm{H}_{2}, 18 \% \mathrm{CO}_{2}, 1.25 \% \mathrm{CH}_{4}, 0.35 \%\right.$ $\mathrm{CO})$ and air. The reformate and air flows were running in counter-flow and the maximum temperature reached was $183^{\circ} \mathrm{C}$, recorded at the centre of the stack.

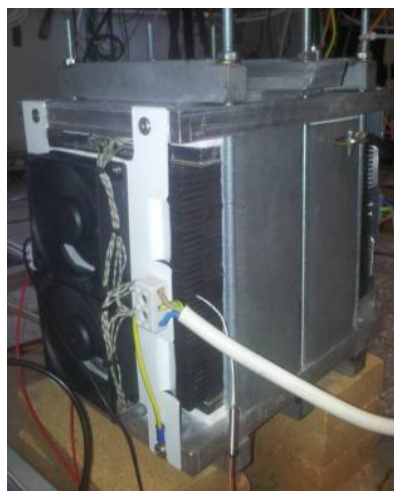

Picture 1: Side view of the $1 \mathrm{~kW}$ air cooled stack.

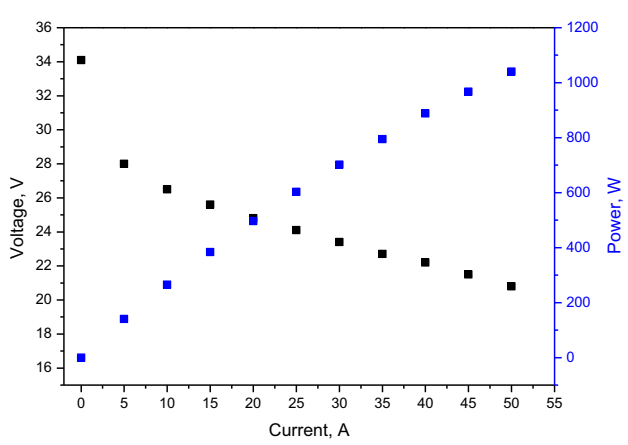

Figure 3. I-V curve of $1 \mathrm{~kW}$ air cooled stack,

Temperature at the center of the stack (highest): $183^{\circ} \mathrm{C}$,

Feed: Reformate gas $\left(1 \mathrm{~m}^{3} / \mathrm{h}\right) /$ air $\left(3.9 \mathrm{~m}^{3} / \mathrm{hr}\right)$.

A new concept of external oil cooling has been recently developed as a continuation and optimization of the air cooled stack, which can be applied over a wider range of applications, including CHP, and can be integrated more efficiently in the thermal balance of the Balance of Plant (BoP) of the fuel processor. The external heating/cooling design approach was successfully developed according to the temperature uniformity and heating/cooling rate limitations. Apart from the cooling design, additional changes have been made on the peripheral structure of the current stack in order to reduce the weight of the final system. Weight and volume optimization of the stack has been achieved through the extensive use of advanced parametric CAD/CAE software (Fig.4). 


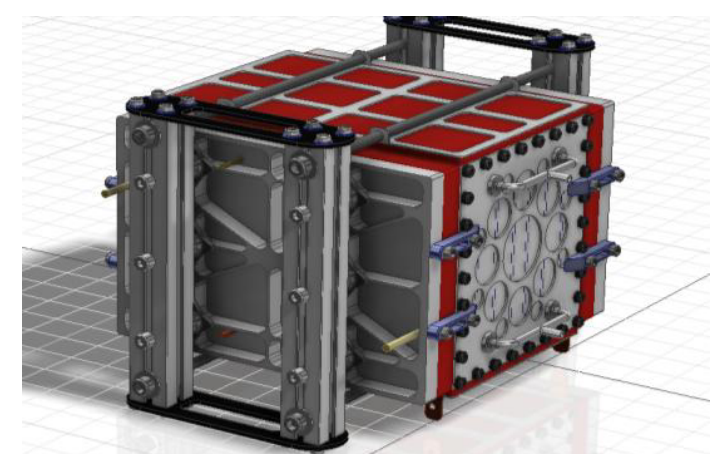

Figure 4: 3D iso view of the liquid cooled stack

Detailed mechanical and thermo-mechanical models have been developed for each part separately in order to predict the stress and strain fields and reduce the weight of the stack. Special attention was given for the uniform distribution of the compression forces over the MEAs through the compression of the specially designed endplates. Moreover the cost development of the final prototype was reduced due to the usage of the aforementioned numerical modeling studies. Advanced alloys and plastics with high specific mechanical properties have been selected, while the selection of the materials for the various parts was based strictly on the optimization of the weight and the final cost.

Based on theoretical calculations, a 41-MEAs stack has been assembled, using MEAs of $177 \mathrm{~cm}^{2}$ area that comprise an optimized cross linked acid-filled membrane. It should be noted that the performance of this type of MEA is lower than those used in the air cooled stack, but were chosen due to their improved tolerance to mechanical stresses and higher operational temperatures. The bipolar plates were of the same material, same active area and design as in the air cooled stack but with fins excluded.

In Picture 2, the oil cooled stack is depicted.

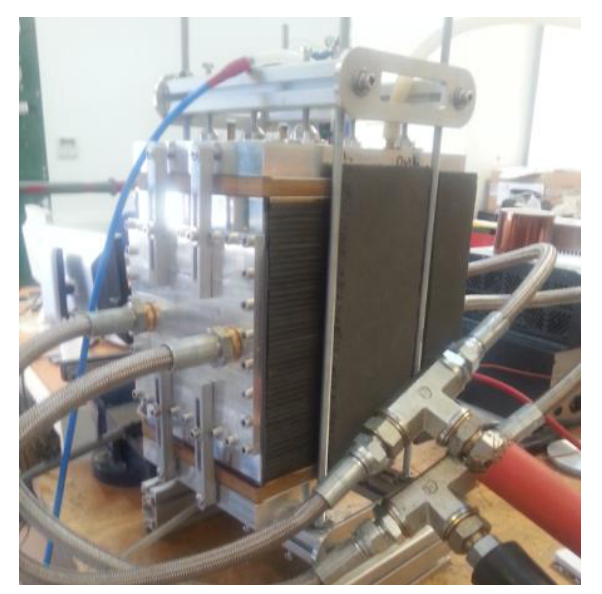

Picture 2: Side view of the $1 \mathrm{~kW}$ liquid cooled stack.

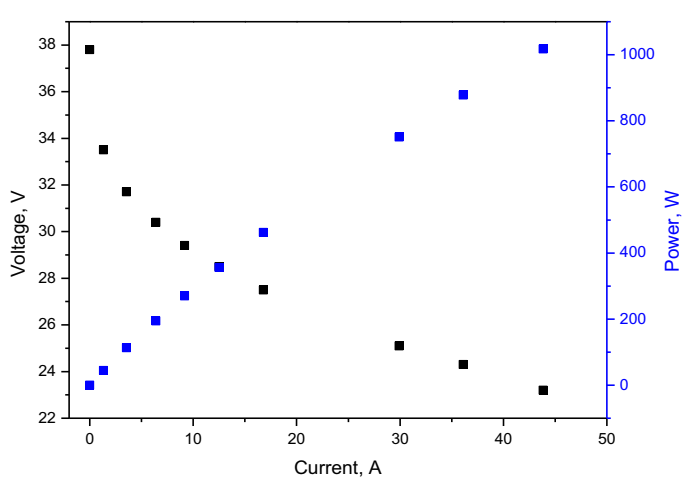

Figure 5. I-V curve of $1 \mathrm{~kW}$ liquid cooled stack, Temperature: $193^{\circ} \mathrm{C}$, Feed: $\mathrm{H}_{2}\left(0.84 \mathrm{~m}^{3} / \mathrm{h}\right) / \mathrm{air}(4$ $\left.m^{3} / h r\right)$.

The MEA performance was consistent and the power output of $1 \mathrm{~kW}$ was reached with hydrogen and air, as shown in Fig. 5.

\subsection{HT PEMFC stacks with metal plates for telecom satellites}

As already mentioned, RFCs (Regenerative fuel cells) are considered a promising alternative for applications requiring either high power levels or missions with long eclipse duration, hence high energy demand, due to their potentially high energy density compared to batteries. Within the framework of ESA Contract No. 4000109578/13/NL/SC, among others, a $3 \mathrm{~kW}$ liquid cooled HT PEMFC stack has been designed. To date, a thorough and extended study has been performed, leading to the selection of the materials that will be used for the realization of the final device. The selected metal and peripheral parts have specific properties in order to achieve a lightweight and reliable structure for space environment according to the specifications set by ESA. Based on our calculations, the dimensions of the bipolar plate are $(105.1 \mathrm{~mm} \times 216.6 \mathrm{~mm})$, with active area equal to $100 \mathrm{~cm}^{2}$ as depicted in Fig.6.
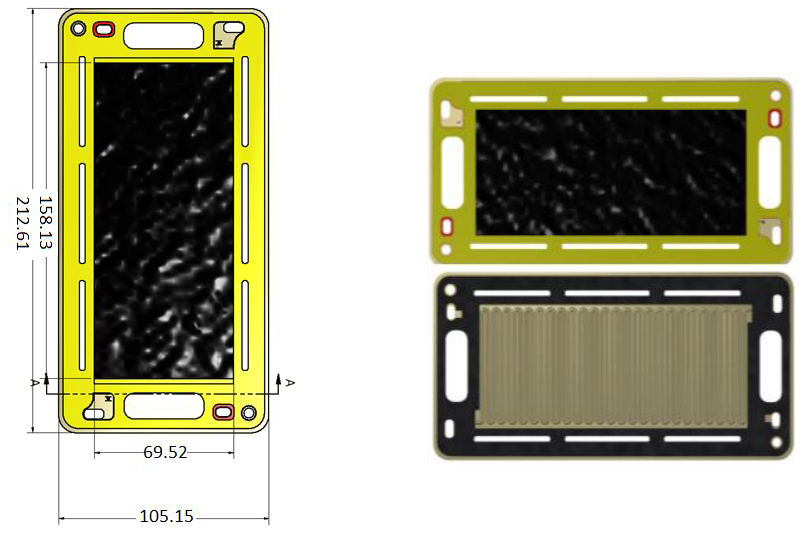

Figure 6. MEA dimensions and bipolar plate cross section. 
The material of bipolar plates was chosen to be Tantalum (99.9\%) coated Titanium alloy. The iso-view drawings of the HT PEMFC stack are presented in Fig. 7.

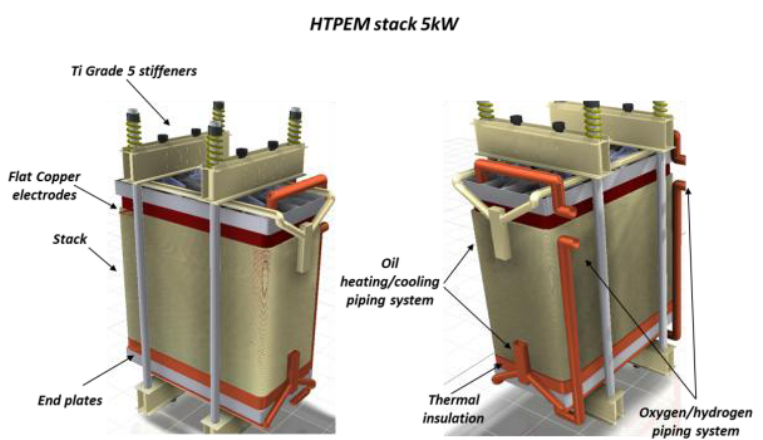

Figure 7. Two iso-views of the HT PEMFC stack and the various parts.

For the metal stack design, the heating/cooling approach will be different compared to the graphitic HT PEMFC stack presented in section 2.1. The coolant/heating oil will flow inside the rectangular channels of all the bipolar plates, as can be observed in the detail drawing of Fig. 8.

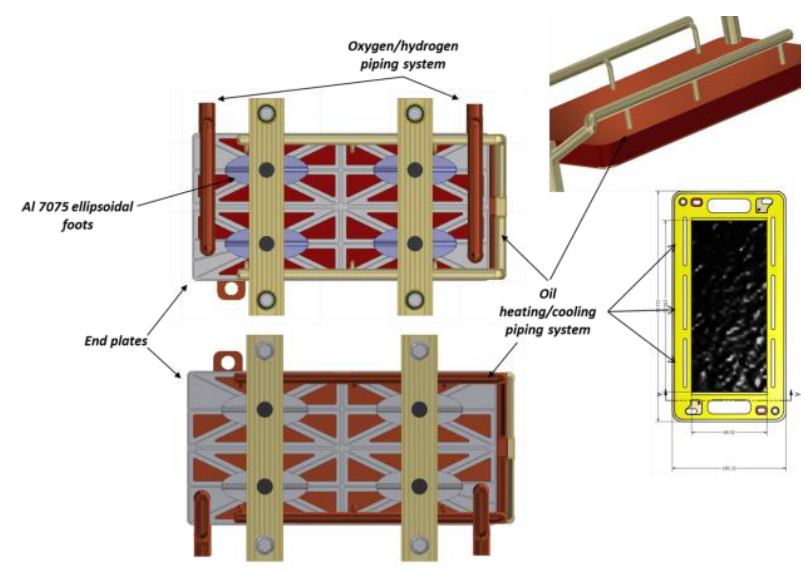

Figure 8. Two different plan-views of the $3 \mathrm{~kW} \mathrm{HT}$ PEMFC stack where internal heating/cooling is represented.

Different design approaches have been considered in order to simulate the final power density of the stack using various thicknesses of the bipolar plate and Tantalum coating. According to calculations and designs, the maximum power density of a $5 \mathrm{~kW}$ stack is $1.2 \mathrm{~kg} / \mathrm{kW}$ and can be achieved if $14.5 \mu \mathrm{m}$ Tantalum coating and Titanium bipolar plate of $0.1 \mathrm{~mm}$ thickness are used. This power density is within that needed for viable satellite applications. Further progress is currently underway.

\section{Acknowledgements}

Funding from the EU's Seventh Framework Program (FP7/2007-2013) for the FCH JTI under the grant agreements 325358 IRMFC and 325368 DeMStack, as well as from the European Space Agency under the Contract No. 4000109578/13/NL/SC.

\section{References}

${ }^{1} Y u$, S., Xiao L. \& Benicewicz B.C. (2008). Durability Studies of PBI-based High Temperature PEMFC. Fuel Cells 8(3-4), 165-174.

${ }^{2}$ Kallitsis, J.K., Andreopoulou, A.K., M.K. Daletou \& Neophytides, S. (2016). Pyridine Containing Aromatic Polyether Membranes, Ch. 5 in "High Temperature Polymer Electrolyte Fuel Cells- Approaches, Status and Perspectives", J.O. Jensen, D. Aili, H.A. Hjuler, Q. Li (Eds.), 91-126.

${ }^{3} \mathrm{http}: / /$ fuelcell.com/wpcontent/uploads/2013/10/Advent-MEA-ProductSheet.pdf 